\title{
Discours
}

Revue de linguistique, psycholinguistique et

informatique. A journal of linguistics, psycholinguistics and computational linguistics

$18 \mid 2016$

Varia

\section{The Role of Discourse Prominence in Antecedent Search: The Case of Genitive Noun Phrases}

Shelia M. Kennison

URL: http://journals.openedition.org/discours/9202

DOI: 10.4000/discours.9202

ISSN: 1963-1723

Publisher:

Laboratoire LATTICE, Presses universitaires de Caen

\section{Electronic reference}

Shelia M. Kennison, «The Role of Discourse Prominence in Antecedent Search: The Case of Genitive Noun Phrases », Discours [Online], 18 | 2016, Online since 16 September 2016, connection on 03 May 2019. URL : http://journals.openedition.org/discours/9202 ; DOI : 10.4000/discours.9202 

Revue de linguistique, psycholinguistique et informatique

\section{The Role of Discourse Prominence}

\section{in Antecedent Search:}

\section{The Case of Genitive Noun Phrases}

Shelia M. Kennison

Department of Psychology

Oklahoma State University, Stillwater

Shelia M. Kennison, «The Role of Discourse Prominence in Antecedent Search: The Case of Genetive Noun Phrases», Discours [En ligne], 18 | 2016, mis en ligne le 16 septembre 2016.

URL: http://discours.revues.org/9202 



\title{
The Role of Discourse Prominence \\ in Antecedent Search: The Case of Genitive Noun Phrases
}

\author{
Shelia M. Kennison \\ Department of Psychology \\ Oklahoma State University, Stillwater
}

\begin{abstract}
The research investigated how readers comprehended reflexive pronoun anaphors (e.g., himself or herself) that occurred in the same sentence with an antecedent that was modified by a genitive noun phrase (NP). Prior research suggested that during the search for an antecedent, readers consider only those preceding discourse entities that are prominent in the discourse; thus, genitive NPs would not be considered because they lack discourse prominence (Badecker \& Straub, 2002). Two reading experiments tested this claim. In Experiment 1, genitive NPs were noun descriptions that were strongly stereotyped for gender (e.g., "The executive's/secretary's father cut himself..."). In Experiment 2, genitive NPs were gender-specific proper names (e.g., "John's/Mary's father cut himself..."), similar to those used in the prior research. The results indicated that genitive NPs that were strongly stereotyped for gender influenced sentence processing time, but genitive NPs that were gender-specific proper names did not; thus, genitive NPs are not uniformly excluded from consideration during the resolution of reflexive pronouns.
\end{abstract}

Keywords: discourse prominence, anaphors, genitive noun phrases, comprehension

\section{Introduction}

When a pronoun is encountered during language comprehension, the comprehender engages in processing that is described as a search for the appropriate antecedent. The memory representation of the discourse that has been processed up to that point is searched, resulting in a set of candidate antecedents. From this set, the comprehender selects the appropriate antecedent. Prior research has investigated which preceding discourse entities are considered as potential antecedents (Badecker \& Straub, 2002; Clifton et al., 1997; Cowart \& Cairns, 1987; Garrod \& Terras, 2000; Kennison, 2003; Kennison et al., 2009; Nicol \& Swinney, 1989; Sturt, 2003; Sun \& Kennison, 2015; Xiang et al., 2009). The present research investigated how readers link reflexive pronouns (e.g., bimself and herself) with potential antecedents.

Chomsky's (198I) "Binding Theory" (BT) described the interpretation of pronouns and reflexives as universally governed by structural principles. It was shown that pronouns and reflexives appear in complimentary distribution (i.e., pronouns appear in structural positions in which reflexives do not, and vice versa). Consider the examples in [r]. 
[I] a. Bill said that Mary liked him.

b. *Bill said that Mary liked himself.

c. Bill $\mathrm{i}_{\mathrm{i}}$ saw himself.

d. *Bill saw him.

The pronoun bim can refer to Bill in [Ia]; however, the reflexive bimself cannot refer to Bill in [Ib]. The reflexive bimself can refer to Bill in [Ic]; however, the pronoun bim cannot, as shown in [Id]. It was further argued that pronouns are not c-commanded by their antecedents; however, reflexives are c-commanded by their antecedents (see Radford, 1988, for description of c-command). These observations were summarized in two principles: Principle $A$, which refers to the fact that a reflexive is generally c-commanded by its antecedent and Principle $B$, which refers to the facts that a pronoun cannot be c-commanded by its antecedent. Since the early I980s, there have been extensions of BT (Chomsky, 198I and 1995; Fiengo \& May, 1994; Manzini \& Wexler, 1987) as well as alternative approaches (Reinhart \& Reuland, 1993; Reuland, 20II). Nevertheless, recent cross-linguistic research calls into question BT's universality (Reuland, 2016).

The extent to which the structural principles affect the selection of an antecedent during antecedent search has been investigation in numerous empirical studies (Badecker \& Straub, 2002; Clifton et al., 1997; Cowart \& Cairns, 1987; Dillon, 20II; Dillon et al., 2013; Garrod \& Terras, 2000; Jäger et al., 2015; Kennison, 2003 and 2013; Kennison et al., 2009; Kennison \& Trofe, 2003; Koornneef \& Sanders, 2013; Nicol \& Swinney, 1989; Sturt, 2003; Sun \& Kennison, 2015). In 1989, Nicol and Swinney provided support for the view that during co-reference resolution comprehenders use structural information to limit the initial set of candidate antecedents (see also Clifton et al., 1997; Sturt, 2003).

The view that structural information is used to restrict the initial set of candidate antecedents was convincingly refuted by Badecker and Straub (2002). In a series of experiments, Badecker and Straub (2002) investigated how readers used structural information during the comprehension of pronouns. They observed that co-reference resolution of a pronoun or reflexive pronoun was influenced by a preceding discourse entity that was not in a structural position within the sentence permitting it to be an antecedent. Consider the sentences in [2].

[2] a. John $n_{\mathrm{i}}$ thought that Bill owed him $\mathrm{i}_{\mathrm{i}}$ another chance to solve the problem.

b. John $n_{\mathrm{i}}$ thought that Jane owed him another chance to solve the problem.

A discourse entity occurring in the subject position of the main clause (i.e., $J o h n)$ can be an antecedent for the pronoun him, i.e., it is structurally available as an antecedent. A discourse entity occurring in the subject position of the subordinate clause (i.e., Bill or Jane) cannot be an antecedent for the pronoun bim, i.e., it is structurally unavailable as an antecedent. Badecker and Straub (2002) found that reading time was longer when the gender of the structurally unavailable entity matched the gender of the structurally available antecedent as in [Ia], than when 
the genders mismatched, as in [Ib]. These results contrasted with prior research suggesting that structurally unavailable discourse entities were excluded from the initial set of candidate antecedents (Clifton et al., 1997; Nicol \& Swinney, 1989; cf. Kennison, 2003; Sturt, 2003).

Badecker and Straub (2002) found that the resolution of reflexive pronouns was also influenced by the characteristics associated with structurally unavailable antecedents. Consider the examples in [3].

[3] a. John thought that Bill owed himself another chance to solve the problem.

b. Jane thought that Bill owed himself another chance to solve the problem.

A discourse entity occurring in the subject position of the subordinate clause (i.e., Bill) can be an antecedent for the reflexive pronoun, but a discourse entity occurring in the subject position of the main clause (i.e., John or Jane) cannot be an antecedent for the reflexive pronoun (BT's Principle A, Chomsky, 198I). Badecker and Straub (2002) found that reading time was longer when the gender of the structurally unavailable proper name was the same as the structurally available antecedent, as in [3a], than when the genders differed, as in [3b].

In another experiment, Badecker and Straub's (2002) failed to find the same pattern of processing in sentences in which a genitive noun phrase (NP) was structurally unavailable as an antecedent for a following reflexive pronoun. They tested sentences similar to those in [4].

[4] a. Jane thought that Bill's brother owed himself another opportunity to solve the problem.

b. Jane thought that Beth's brother owed himself another opportunity to solve the problem.

A discourse entity occurring as the subject of the subordinate clause (i.e., brother) is structurally available as an antecedent for the reflexive pronoun. A discourse entity occurring in the subject position of the main clause (i.e., Jane) or occurring in the genitive NP position (i.e., Bill's or Beth's) is structurally unavailable as an antecedent for the reflexive pronoun, as neither position c-commands the reflexive pronoun. Badecker and Straub (2002) observed no significant processing differences between these conditions. They concluded that the genitive NP was excluded from the initial set of candidate antecedent because it lacked prominence in the local discourse. This conclusion was viewed as consistent with prior research showing that genitive NPs are less accessible as referents than the simple NPs within the same major phrase (Gordon et al., 1999). Interestingly, there is no consensus regarding how to determine a discourse entity's prominence. Some researchers have argued that discourse prominence is determined by order of mention in the discourse (Gernsbacher, 1990; Walker \& Prince, 1996). Gordon et al. (1999) suggests that discourse prominence varies for types of discourse entities with some types being more prominent than others. 
The processing of reflexives, generally, and Badecker and Straub's (2002) results involving reflexives, specifically, are of importance to theories in which comprehension is envisioned as a content addressable architecture (Dillon, 20II; Dillon et al., 2013; Lewis \& Vasishth, 2005). Dillon and colleagues (Dillon, 20II; Dillon et al., 2013) argued that the patterns of processing observed in studies of pronoun processing can interpreted as reflecting interference (i.e., encoding interference). Dillon et al. (2013) carried out a series of studies in which they compared processing time on sentences containing subject-verb agreement errors vs. grammatical control sentence with processing time on sentences containing antecedent-reflexive agreement errors with grammatical controls. For both types of constructions, they varied the characteristics of an intervening noun. Examples presented in [5].

[5] a. The new executive who oversaw the middle manager(s) apparently was dishonest...

b. The new executive who oversaw the middle manager(s) apparently were dishonest...

c. The new executive who oversaw the middle manager(s) apparently doubted himself...

d. The executive who oversaw the middle manager(s) apparently doubted themselves...

Overall processing time was longer for ungrammatical conditions vs. grammatical conditions (i.e., a vs. b and c vs. d). The characteristics of the intervening noun manager or managers interacted with grammatically to determine reading time for sentences in which subject-verb agreement was varied (i.e., a vs. b), but not for sentences in which antecedent-reflexive agreement was varied (i.e., c vs. d). Thus, there was an intrusion effect when readers processed sentences containing subject verb agreement, but not for sentences containing a reflexive. In recent research, the failure to find intrusion effects in sentences containing a reflexive have been replicated (Jäger et al., 2015); however, relying on evidence from German and Swedish, the authors argue convincingly that interference occurs during retrieval rather than during encoding in sentences containing a reflexive.

The focus of the present research was to investigate further how antecedent search occurs during the processing of reflexive pronouns. Specifically, the research examined Badecker and Straub's (2002) conclusion that only those entities that are prominent in the discourse are included in the set of potential antecedents. Many researchers have recognized that discourse prominence plays a role in the comprehension of pronouns (Clifton \& Ferreira, 1987; Gordon et al., 1993; Gordon et al., 1999; Grosz et al., 1995: Gundel et al., 1993; Reinhart \& Reuland, 1993). Processing is facilitated when a pronoun is interpreted as referring to an antecedent that is high in discourse prominence (i.e., apparent importance) as compared to an antecedent lower in discourse prominence (Grosz et al., 1995; Gundel et al., 1993). The present research specifically investigated the extent to which genitive NPs are excluded from consideration in antecedent search due to their low discourse prominence. Two reading comprehension experiments were conducted in which reading time was measured on sentences containing 
a reflexive pronoun (i.e., bimself or herself). The subject of each sentence was a complex NP containing the unambiguous antecedent for the reflexive pronoun and a genitive NP. The genders of the genitive NP and the unambiguous antecedent were either the same (i.e., matching) or different (i.e., mismatching). Reading time was measured using a self-paced moving window. Sample sentences from Experiment $\mathrm{I}$ are presented in [6].

[6] Gender Mismatching Conditions

a. The executive's mother talks to herself when no one else is around.

b. The secretary's father talks to himself when no one else is around.

Gender Matching Conditions

c. The executive's father talks to himself when no one else is around.

$\mathrm{d}$. The secretary's mother talks to herself when no one else is around.

The impetus for the present research was the consideration of an alternative possible outcome, one in which genitive NPs are included in the set of candidate antecedents. In the present approach, it was considered possible that Badecker and Straub (2002) failed to detect an effect that exists. The comprehension of a pronoun in relation to an antecedent is a dynamic process unfolding over time in which discourse information is being used relatively late (Garrod, 1994; Garrod \& Sanford, 1994; Garrod \& Terras, 2000; Sanford et al., 1983; Sturt, 2003). In sentence parsing research, the use of discourse information has also been shown to be used relatively late in processing of syntactically ambiguous phrases (Britt et al., 1992).

In the two experiments that are reported in this paper, the type of genitive NP occurring in sentences with a reflexive pronoun was varied. In Experiment I, the genitive NPs were noun descriptions (e.g., the executive's and the secretary's). In Experiment 2, the genitive NPs were proper names (e.g., John or Mary). In accordance with Badecker and Straub's (2002) claim, the processing of reflexive pronouns were expected not to be influenced by characteristics associated with genitive NPs, because genitive NPs are low in discourse prominence. Further, because prior research has shown that there are processing differences for proper names and noun descriptions in speech production (Burke et al., I99I; Cohen, I990; Cohen \& Burke, 1993) and in discourse comprehension (Sanford et al., 1988), it was reasoned that results in Experiments I and 2 were considered possible. In the speech production literature, proper names are viewed as having less semantic content than descriptions, which can lead to more tip-of-the-tongue states for names than for noun descriptions. In contrast, in an investigation of the resolution of pronouns in short discourses (i.e., four sentences long with the pronoun occurring in the fourth sentence and a name or noun description occurring in the first sentence), Sanford et al. (1988) found that readers' processing time was faster for proper name antecedents than noun description antecedents in discourses where the antecedent occurred three sentences back in the discourse (Sanford et al., 1988). 


\section{Experiment 1}

The purpose of Experiment I was to investigate whether genitive NPs that were strongly stereotyped noun descriptions would influence the processing of a reflexive pronoun occurring later in the sentence. Table I displays sample items with presentation regions indicated by slashes.

\subsection{Method}

\subsubsection{Participants}

Sixty undergraduates at Oklahoma State University participated for course credit. All were native speakers of American English and were naive to the purposes of the experiment. Using G*Power 3.I (Faul et al., 2007; Faul et al., 2009), it was determined that the number of participants tested in the experiment resulted in sufficient power to detect medium, large, as well as small effect sizes.

\subsubsection{Materials}

Sixteen sets of experimental sentences were constructed. Each set of sentences contained four versions. An example set of sentences is presented in Table I. Two versions contained the reflexive pronoun bimself, and two contained the reflexive pronoun berself. The female or male antecedent was unambiguous, i.e., genderspecific by definition, such as mother and father. The gender of the genitive NP either matched or mismatched the gender of the antecedent. The genitive NP was either gender-specific by definition (e.g., groom, bride) or strongly stereotyped. The strength of the gender stereotype for each NP used as a genitive NP was obtained from normative data reported in Kennison and Trofe (2003). Participants rated nouns and noun compounds on a scale from I $(I=$ refers mostly to females $)$ to 7 $(7=$ refers mostly to males $)$. For the genitive NPs used in the present materials, those stereotyped to refer to males and females had the following mean ratings: male: 5.58 $(S D=0.87)$ and female: $2.16(S D=0.85)$. A complete list of experimental sentences is provided in Appendix A.

\subsubsection{Procedure}

Sentences were presented on a cathode ray tube monitor controlled by MicroExperimental Laboratory Professional II (MEL2) on an IBM compatible microcomputer. Sentences were presented using a phrase-by-phrase self-paced moving window using preview dashes (Kennedy \& Murray, 1984). For each trial, a series of preview dashes were displayed representing each letter and space of the sentence to be presented. When the reader pressed the "/-key" for the first time, the first presentation region of the sentence appeared, replacing the corresponding dashes. When the reader completed reading the first presentation region and pressed the key again, the second presentation region appeared, replacing the corresponding dashes; the first presentation region was removed and replaced with corresponding dashes. This procedure was repeated until the last presentation region was read. Participants 


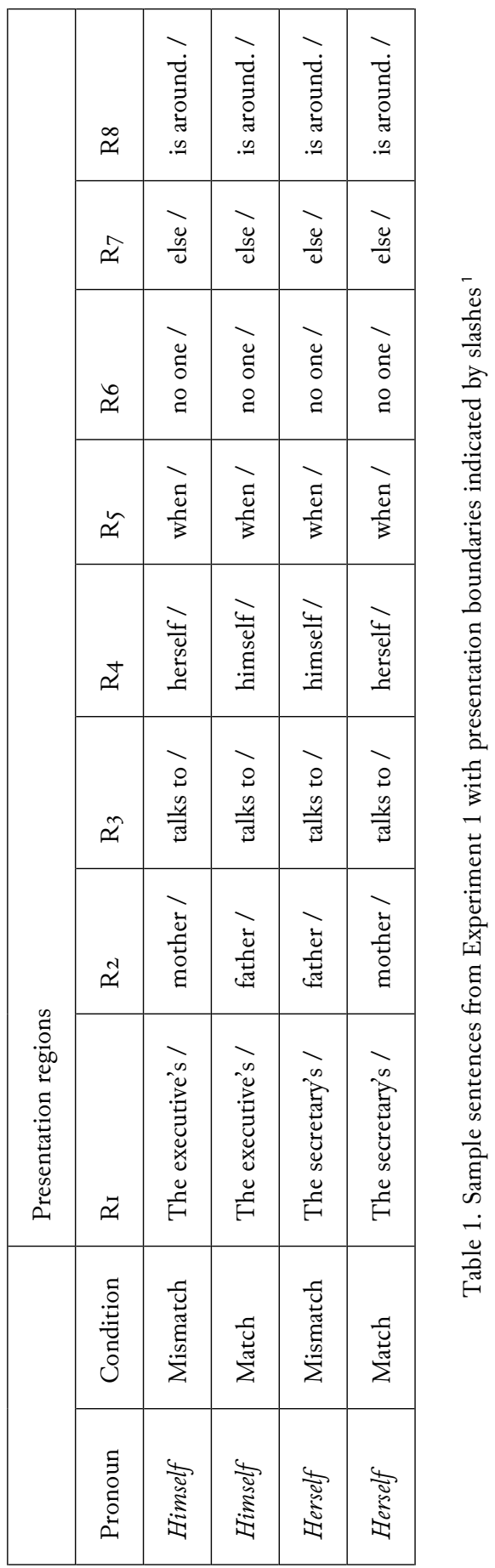


used the "/-key" to advance the presentation of the sentence and the "z-key" and " $\mathrm{x}$-key" for YES/NO responses to comprehension questions, respectively. The session began with each participant viewing 16 practice sentences followed by the experimental set, which contained 16 target sentences randomized intermixed with 84 filler sentences, which did not contain any type of pronoun. Each participants viewed the sentences in a unique random order. Each sentence in the session was followed by a comprehension question. Comprehension questions for targets were straightforward, avoiding direct reference to the reflexive pronoun, the antecedent of the reflexive pronoun, nor the genitive NP. Filler sentences did not contain pronouns and contained a variety of syntactic structures. Four counterbalancing lists were used to ensure that each item was viewed in each condition equally often across participants. Each participant was tested individually in a private well-lit cubicle. Each session lasted between 30 and 45 minutes.

\subsection{Results}

Accuracy to comprehension questions was $95 \%$, indicating that participants had complied with instructions to comprehend sentences. Reading times observed at each presentation region were initially trimmed; observations shorter than Ioo milliseconds were eliminated. Observations longer than 3 standard deviations above or below the mean reading time for the participant were eliminated. Less than $1 \%$ of observations were removed. Table 2 displays mean reading time in milliseconds for each presentation region by condition. All ANOVAs (analyses of variance) reported in this paper were carried out using participants $\left(F_{1}\right)$ and items $\left(F_{2}\right)$ as random effects, following Clark (1973). Mean reading time was analyzed for each presentation region. The two within-subjects factors were pronoun gender (i.e., bimself vs. berself) and condition (gender match vs. mismatch). Participants took longer to read the region following the reflexive pronoun in gender mismatch conditions vs. gender match conditions: $F_{\mathrm{I}}(\mathrm{I} .59)=8.36, p=0.005, n^{2}=0.8 \mathrm{r}$; $F_{2}(\mathrm{I} .15)=\mathrm{I3} .4 \mathrm{I}, p=0.002, n^{2}=0.93$. There were no other presentation regions for which reading time varied significantly: $F_{s}<2.66, p>0.05$. No other main effects or interactions were significant.

\subsection{Discussion}

The results supported the conclusion that entities low in discourse prominence, such as genitive NPs, are not generally excluded from the initial set of candidate antecedents. An important question remains concerning why a gender mismatch effect (i.e., longer reading time in gender mismatch vs. gender match conditions) was observed in the present experiment, but not observed by Badecker and Straub (2002). The type of genitive NP that was used in the present experiment differed from those used by Badecker and Straub (2002). The genitive NPs in the prior research were gender-specific proper names (e.g., Jobn, and Mary). The purpose of Experiment 2 was to determine whether the results of the present study could be obtained when using materials similar to those used in the prior research. 


\begin{tabular}{|c|c|c|c|c|c|c|c|c|}
\hline \multirow[b]{2}{*}{$\begin{array}{l}\text { Himself } \\
\text { Conditions }\end{array}$} & \multicolumn{8}{|c|}{ Presentation regions } \\
\hline & RI & $\mathrm{R}_{2}$ & $\mathrm{R}_{3}$ & $\mathrm{R}_{4}$ & $\mathrm{R}_{5}$ & R6 & $\mathrm{R}_{7}$ & R8 \\
\hline \multirow[t]{2}{*}{ Mismatch } & 650 & 633 & $58 \mathrm{I}$ & $5 \mathrm{IO}$ & 495 & 512 & 480 & 653 \\
\hline & (33) & （37） & (27) & $(24)$ & $(22)$ & $(22)$ & $(2 \mathrm{I})$ & (32) \\
\hline \multirow[t]{2}{*}{ Match } & 608 & 593 & 582 & 482 & 445 & 506 & 485 & 667 \\
\hline & (3I) & (36) & (3I) & (19) & (17) & (20) & $(22)$ & (30) \\
\hline $\begin{array}{l}\text { Herself } \\
\text { Conditions }\end{array}$ & RI & $\mathrm{R}_{2}$ & $\mathrm{R}_{3}$ & $\mathrm{R}_{4}$ & $\mathrm{R}_{5}$ & R6 & $\mathrm{R}_{7}$ & R8 \\
\hline \multirow[t]{2}{*}{ Mismatch } & $63 \mathrm{I}$ & 557 & $54 \mathrm{I}$ & 499 & $5 \mathrm{OI}$ & 495 & 467 & 652 \\
\hline & (32) & (28) & (23) & $(2 \mathrm{I})$ & (23) & $(2 \mathrm{I})$ & (I6) & (29) \\
\hline \multirow[t]{2}{*}{ Match } & $64 \mathrm{I}$ & $56 \mathrm{I}$ & 602 & 543 & 459 & 490 & 479 & 664 \\
\hline & (36) & (38) & (34) & (3I) & (17) & (I8) & (I8) & (39) \\
\hline
\end{tabular}

Table 2. Mean reading time in milliseconds (and standard errors) by presentation region for each condition in Experiment $1^{2}$

\section{Experiment 2}

Reading time was measured on sentences similar to those tested in Experiment I. In the present experiment, all genitive NPs were gender-specific proper names, as was the case in Badecker and Straub's (2002) experiment.

\subsection{Method}

\subsubsection{Participants}

Fifty-six undergraduates at Oklahoma State University participated for course credit. All were fluent speakers of American English and were naive to the purposes of the experiment. As in Experiment I, G*Power 3.I (Faul et al., 2007; Faul et al., 2009) was used to determine that the number of participants tested in the experiment had sufficient power to detect medium, large, as well as small effect sizes.

\subsubsection{Materials}

Sixteen sets of experimental sentences were constructed. Each set of sentences had four versions. Two versions contained the reflexive pronoun bimself, and two contained the reflexive pronoun berself. The female or male antecedent was by definition male or female (e.g., sister, brother, mother, father, etc.). The genitive NP

2. Region I contained the genitive NP. Region 2 contained the antecedent. Region 4 contained bimself or berself. ${ }^{*} p s<$ o.oI. 
either matched or mismatched in gender with the antecedent. The genitive NP was a proper name with unambiguous gender. A complete list of experimental materials is provided in Appendix B.

\subsubsection{Procedure}

The procedure was the same as in Experiment $\mathrm{I}$.

\subsection{Results and discussion}

Reading times for each presentation region were initially trimmed for outliers, using the same procedure as used in Experiment I. Less than $\mathrm{I} \%$ of observations were removed. Table 3 displays mean reading time in milliseconds for each presentation region by condition. Mean reading time was analyzed for each presentation region using type of reflexive pronoun and condition, condition (i.e., mismatch vs. match), and pronoun gender (i.e., bimself vs. herself). The results of Experiment 2 replicated the results of Badecker and Straub (2002). There was no evidence that genitive NPs influenced the time that readers took to resolve the reflexive pronoun. Gender mismatch conditions were not read significantly slower than gender match conditions at any region: $F s<2.92, p s>0.10$. No other main effects or interactions were significant. The results differ with those observed in Experiment $\mathrm{I}$ in this paper in which reading time following the reflexive pronoun was significantly longer with the gender of the genitive NP mismatched the gender of the antecedent and reflexive pronoun than when the genders matched.

\begin{tabular}{|l|c|c|c|c|c|c|c|}
\hline \multirow{2}{*}{ Himself Conditions } & \multicolumn{6}{|l}{ Presentation regions } \\
\hline \multirow{2}{*}{ Mismatch } & $\mathrm{R}_{\mathrm{I}}$ & $\mathrm{R}_{2}$ & $\mathrm{R}_{3}$ & $\mathrm{R}_{4}$ & $\mathrm{R}_{5}$ & $\mathrm{R} 6$ & $\mathrm{R}_{7}$ \\
\cline { 2 - 9 } & $93 \mathrm{I}$ & 682 & 642 & 598 & 584 & 573 & 787 \\
\hline \multirow{2}{*}{ Match } & $(54)$ & $(38)$ & $(33)$ & $(42)$ & $(24)$ & $(40)$ & $(43)$ \\
\cline { 2 - 9 } & $(583$ & $67 \mathrm{I}$ & 625 & 599 & 579 & 542 & 796 \\
\hline \multirow{2}{*}{ HerselfConditions } & $\mathrm{R}_{\mathrm{I}}$ & $\mathrm{R}_{2}$ & $\mathrm{R}_{3}$ & $\mathrm{R}_{4}$ & $\mathrm{R}_{5}$ & $\mathrm{R} 6$ & $\mathrm{R}_{7}$ \\
\hline \multirow{2}{*}{ Mismatch } & 996 & 660 & 590 & 554 & 597 & 562 & 762 \\
\cline { 2 - 9 } & $(76)$ & $(34)$ & $(34)$ & $(24)$ & $(33)$ & $(28)$ & $(33)$ \\
\hline \multirow{2}{*}{ Match } & $9 \mathrm{II}$ & 648 & 586 & $53 \mathrm{I}$ & 560 & 552 & 787 \\
\cline { 2 - 9 } & $(50)$ & $(28)$ & $(27)$ & $(19)$ & $(20)$ & $(20)$ & $(48)$ \\
\hline
\end{tabular}

Table 3. Mean reading time in milliseconds (standard errors) by presentation region for each condition in Experiment $2^{3}$

3. Region I contained the genitive NP and the antecedent. Region 3 contained the reflexive pronoun. 


\section{General discussion}

The gender mismatch effect that was observed in the present experiment may have occurred because of evaluation processing occurring after comprehenders formed a link between the reflexive pronoun and the antecedent. The evaluation of the established co-reference link may have been influenced by the presence of

The present research investigated how readers carry out antecedent search during the comprehension of reflexive pronouns. Of particular interest was Badecker and Straub's (2002) conclusion that during the resolution of a reflexive pronoun, readers would not consider a previous genitive NP as a candidate antecedent, due to its low discourse prominence. The results call into question this conclusion, because in Experiment I, readers' resolution of a reflexive pronoun was influenced by characteristics associated with a preceding genitive NP. Readers took longer to process reflexive pronouns when the genitive NP mismatched the gender of the pronoun and antecedent as compared with the three entities matched in gender. In Experiment 2, the genitive NPs were proper names, as they were in the studies conducted by Badecker and Straub (2002). No effect of the genitive NP was observed on the time taken to process the reflexive pronoun.

These results support a theory of pronoun comprehension in which the set of candidate antecedents is not restricted based on the discourse entity's structural relationship with the pronoun or reflexive pronoun, the discourse entity's prominence in the discourse, or the discourse entity's lexical gender compatibility with the reflexive pronoun. These sources of information as well as other sources of information most certainly influence the subsequent stages of processing involved in co-reference resolution. Garrod and colleagues (Garrod, I994; Garrod \& Sanford, 1994; Garrod \& Terras, 2000; Sanford et al., 1983; Sturt, 2003) provide excellent suggestions for what these subsequent stages of processing are likely to include. They have proposed the two stages of processing: a) bonding and b) resolution. Bonding occurs when a link is made between the pronoun or reflexive pronoun and one or more candidate antecedents. Resolution involves the evaluation of a link created during the bonding phase and the integration of the link into the semantic interpretation of the sentence. Resolution may also involve re-computation of a link, if it is found to be implausible. The resolution phase may result in a link being successfully integrated into the semantic interpretation of the sentence. Kennison (2003) has proposed an additional stage in which the comprehender may decide to halt antecedent search. This stage is necessary, as there can be circumstances in which there is no antecedent available in the discourse or circumstances in which none of the available links are successfully integrated into the semantic interpretation of the discourse. In these circumstances, comprehenders can halt the search for an antecedent, choosing to move forward in the discourse. At the point that antecedent search is halted, the comprehender may infer that the pronoun or reflexive pronoun refers to an unmentioned entity, or they may maintain multiple possible links until later context can be found to support one of the links as the intended antecedent. 
mismatching lexical features within the noun phrase containing the antecedent and genitive. Bock and colleagues (Bock \& Miller, 1991; Bock \& Eberhard, 1993) have shown that relationship between the lexical features of noun phrases within complex noun phrases can influence performance in language processing tasks. When the grammatical number associated with nouns within a complex NP mismatched, more speech production errors were observed than when the grammatical number of the nouns matched. Interestingly, the mismatching genders of the genitive NP and the head noun of the phrase did not lead to significantly longer reading time as compared to when genders matched as readers processed the phrase itself. The gender mismatch effect occurred only later when readers comprehended the pronoun.

The results add to the literature with regard to processing differences between proper names and noun descriptions. In Experiment 2, when genitive NPs were proper names, the process of antecedent search was not affected in a way that could be detected. On one hand, this may mean that during processing, interference related to proper names is smaller and more difficult to detect in processing studies. Prior research has suggested that proper names are labels without meaning (Cohen $\&$ Burke, 1993); thus, proper names differ in the amount of semantic content than noun descriptions (e.g., doctor and nurse). Other research has shown that people have difficulty learning and remembering proper names (Burke et al., I991; Cohen, 1990). In contrast, here is also prior research by Sanford et al. (1988), showing that in short discourses, pronouns occurring in the fourth sentence of a discourse were comprehended faster when linked with a proper name antecedent than a noun description antecedent when the antecedent was in the first sentence of the discourse. Future research is needed to investigate further how the processing of proper names and noun descriptions differs. This research is needed to develop a comprehensive theory of co-reference resolution.

Future research is also needed to explore further how readers carry out antecedent search for reflexives, specifically whether interference effects are related to encoding (Dillon et al., 2013) or retrieval (Jäger et al., 2015). Such research may be able to explain why the gender mismatch effect observed in the present research occurred relatively early in the processing of the reflexive while the gender match effect reported in Badecker and Straub's (2002) Experiment 3 occurred relatively late in processing, two regions after the reflexive pronoun. One possibility is that readers must always decide when to terminate antecedent search processes (see Kennison, 2003). In Badecker and Straub's (2002) experiments, readers may have taken longer to terminate antecedent search when the set of candidate antecedents contained a discourse entity whose gender matched the pronoun or reflexive pronoun. Following this explanation, the gender mismatch effect and the gender match effect are caused during different stages of processing during co-reference resolution: the gender mismatch effect occurring early on during the stage of bonding or resolution and the gender match effect occurring later during processing. It is also possible that the decision to terminate antecedent search can be influenced by task demands and participants' individual differences (e.g., average processing speed, 
working memory capacity, personality, and possibly others). Task demands would certainly vary between experiments in which participants process only grammatical sentences and experiments in which participants process both grammatical and ungrammatical sentences (Dillon et al., 2013). Generally speaking, participants who experience ungrammatical sentences during an experimental session may be inclined to terminate antecedent search sooner on a given trial than those participants who experience only grammatical sentences in a session. Participants' level of engagement in the task may be reduced by the presence of ungrammatical trials in the session. When comparing results from experiments involving only grammatical sentences, participants' level of engagement may also influenced by the percentage of trials on which comprehension questions occur. In the present research, they occurred after every trial. In Badecker and Straub's (2002) studies, they occurred on only $25 \%$ of the trials.

In sum, the results reported in this paper support a view of co-reference resolution in which readers generate a set of candidate antecedents that includes all previously encountered discourse entities. Readers do not appear to use information about the discourse entities' discourse prominence, structural position or lexical compatibility with the reflexive pronoun to restrict the set. However, it is suggested that readers use these sources of information during subsequent stages of processing. Such stages of processing may include forming links between referents and their structurally available antecedents, in integrating the interpreting of those links into the discourse representation, and in deciding to halt the search for an antecedent.

\section{References}

Ariel, M. 1990. Accessing Noun-Phrase Antecedents. London - New York: Routledge.

BadeckeR, W. \& Straub, K. 2002. The Processing Role of Structural Constraints on the Interpretation of Pronouns and Anaphors. Journal of Experimental Psychology: Learning, Memory, and Cognition 28 (4): 748-769.

Bock, K. \& Eberhard, K.M. 1993. Meaning, Sound, and Syntax in English Number Agreement. Language and Cognitive Processes 8 (I): 57-99.

Bock, K. \& Miller, C.A. 1991. Broken Agreement. Cognitive Psychology 23 (I): 45-93.

Britt, M.A., Perfetti, C.A., Garrod, S. \& Rayner, K. 1992. Parsing in Discourse: Context Effects and Their Limits. Journal of Memory and Language 3I (3): 293-314.

Burke, D.M., Mackay, D.G., Worthley, J.S. \& Wade, E. 199i. On the Tip of the Tongue: What Causes Word Finding Failures in Young and Older Adults. Journal of Memory and Language 30 (5): 542-579.

Сномsкy, N. 1981. Lectures on Government and Binding: The Pisa Lectures. DordrechtCinnaminson: Foris Publications.

Сномsкy, N. 1995. The Minimalist Program. Cambridge - London: MIT Press.

Clark, H.H. 1973. The Language-as-Fixed-Effect Fallacy: A Critique of Language Statistics in Psychological Research. Journal of Verbal Learning and Verbal Behavior I2: 335-359. 
Clifton, C. Jr. \& Ferreira, F. 1987. Discourse Structure and Anaphora: Some Experimental Results. In M. Coltheart (ed.), The Psychology of Reading. Attention and Performance XII. Hove - London - Hillsdale: L. Erlbaum: 635-654.

Clifton, C. JR., Kennison, S.M. \& Albrecht, J.E. 1997. Reading the Words "Her", "His", and "Him": Implications for Parsing Principles Based on Frequency and Structure. Journal of Memory and Language 36 (2): 276-292.

Cohen, G. 1990. Why Is It Difficult to Put Names to Faces? British Journal of Psychology 8I (3): $287-297$.

Cohen, G. \& Burke, D.M. 1993. Memory for Proper Names: A Review. Memory I (4): $249-263$.

Cowart, W. \& Cairns, H.S. 1987. Evidence for an Anaphoric Mechanism within Syntactic Processing: Some Reference Relations Defy Semantic and Pragmatic Constraints. Memory and Cognition I5 (4): 318-33I.

Dillon, B.W. 2orr. Structured Access in Sentence Comprehension. PhD thesis. University of Maryland.

Dillon, B.W., Mishler, A., Sloggett, S. \& Phillips, C. 20I3. Contrasting Intrusion Profiles for Agreement and Anaphora: Experimental and Modeling Evidence. Journal of Memory and Language 69 (2): 85-103.

Faul, F., Erdfelder, E., Buchner, A. \& Lang, A.-G. 2009. Statistical Power Analyses Using G*Power 3.I: Tests for Correlation and Regression Analyses. Behavior Research Methods 4I (4): II49-II6O.

Faul, F., Erdfelder, E., Lang, A.-G. \& Buchner, A. 2007. G*Power 3: A Flexible Statistical Power Analysis Program for the Social, Behavioral, and Biomedical Sciences. Bebavior Research Methods 39 (2): I75-I9I.

FIEngo, R. \& MAY, R. 1994. Indices and Identity. Cambridge: MIT Press.

Francis, W.N. \& KuČERA, H. 1982. Frequency Analysis of English Usage: Lexicon and Grammar. Boston: Houghton Mifflin.

Garnham, A. 20or. Mental Models and the Interpretation of Anaphora. Hove: Psychology Press.

Garrod, S. 1994. Resolving Pronouns and Other Anaphoric Devices: The Case for Diversity in Discourse Processing. In C. Clifton Jr., L. Frazier \& K. Rayner (eds.), Perspectives on Sentence Processing. Hillsdale: L. Erlbaum: 339-359.

Garrod, S. \& Sanford, A.J. 1994. Resolving Sentences in a Discourse Context: How Discourse Representation Affects Language Understanding. In M.A. Gernsbacher (ed.), Handbook of Psycholinguistics. San Diego - London: Academic Press: 675-698.

Garrod, S. \& Terras, M. 200o. The Contribution of Lexical and Situational Knowledge to Resolving Discourse Roles: Bonding and Resolution. Journal of Memory and Language $42(4): 526-544$.

Gernsbacher, M.A. 1990. Language Comprehension as Structure Building. Hillsdale: L. Erlbaum.

Gordon, P., Grosz, B.J. \& Gilliom, L. 1993. Pronouns, Names, and the Centering of Attention in Discourse. Cognitive Science I7 (3): 311-347. 
Gordon, P., Hendrick, R., Ledoux, K. \& Yang, C.L. 1999. Processing of Reference and the Structure of Language: An Analysis of Complex Noun Phrases. Language and Cognitive Processes I4 (4): 353-379.

Grosz, B.J., Joshi, A.K. \& Weinstein, S. i995. Centering: A Framework for Modeling the Local Coherence of Discourse. Computational Linguistics 2I (2): 203-225.

Gundel, J.K., Hedberg, N. \& Zacharski, R. 1993. Cognitive Status and the Form of Referring Expressions in Discourse. Language 69 (2): 274-307.

JäGer, L.A., BenZ, L., Roeser, J., Dillon, B.W. \& VAsishth, S. 20I5. Teasing Apart Retrieval and Encoding Interference in the Processing of Anaphors. Frontiers in Psychology 6: 506. Available online: http://journal.frontiersin.org/article/ı0.3389/fpsyg.2015.00506/full.

Kennedy, A. \& Murray, W.S. 1984. Inspection Times for Words in Syntactically Ambiguous Sentences under Three Presentation Conditions. Journal of Experimental Psychology: Human Perception and Performance Io (6): 833-847.

Kennison, S.M. 2003. Comprehending the Pronouns "Her", "Him", and "His": Implications for Theories of Referential Processing. Journal of Memory and Language 49 (3): 335-352.

Kennison, S.M. 20I3. Introduction to Language Development. Thousand Oaks: Sage Publications.

Kennison, S.M., Fernandez, E.C. \& Bowers, J.M. 2009. Processing Differences for Anaphoric and Cataphoric Pronouns: Implications for Theories of Discourse Processing. Discourse Processes 46 (I): 25-45.

Kennison, S.M. \& Trofe, J.L. 2003. Comprehending Pronouns: A Role for Word-Specific Gender Stereotype Information. Journal of Psycholinguistic Research 32 (3): 355-378.

KoornneEF, A.W. \& SAnders, T.J.M. 20I3. Establishing Coherence Relations in Discourse: The Influence of Implicit Causality and Connectives on Pronoun Resolution. Language and Cognitive Processes 28 (8): I169-I206.

Lewis, R.L. \& VAsishth, S. 2005. An Activation-Based Model of Sentence Processing as Skilled Memory Retrieval. Cognitive Science 29 (3): 375-419.

Manzini, R. \& WeXler, K. I987. Parameters, Binding Theory, and Learnability. Linguistic Inquiry I8 (3): 413-444.

Nicol, J. \& Swinney, D. 1989. The Role of Structure in Co-reference Assignment during Sentence Comprehension. Journal of Psycholinguistic Research I8 (I): 5-20.

RAdFord, A. 1988. Transformational grammar. Cambridge: Cambridge University Press [2nd edition].

Reinhart, T. 1983. Anaphora and Semantic Interpretation. London: Croom Helm.

Reinhart, T. \& Reuland, E. 1993. Reflexivity. Linguistic Inquiry 24 (4): 657-720.

Reuland, E. 2oir. Anaphora and Language Design. Cambridge - London: MIT Press.

REUland, E. 2016 (in press). Grammar of Binding in the Languages of the World: Unity versus Diversity. Cognition. Available online: http://www.sciencedirect.com/science/

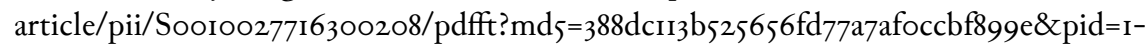
s2.o-Sooroo27716300208-main.pdf.

Sanford, A.J., Garrod, S., Lucas, A. \& Henderson, R. 1983. Pronouns without Explicit Antecedents? Journal of Semantics 2 (3-4): 303-318. 
SAnford, A.J., Moar, K. \& Garrod, S. 1988. Proper Names as Controllers of Discourse Focus. Language and Speech 3I (I): 43-56.

Sturt, P. 2003. The Time-Course of the Application of Binding Constraints in Reference Resolution. Journal of Memory and Language 48 (3): $542-562$.

Sun, B. \& Kennison, S.M. 20I5. Comprehending Pronouns in Chinese: Evidence for Cross-Language Differences in Referential Processing. Language Sciences 47 (I): 56-65.

VAN DYKe, J.A. 2007. Interference Effects from Grammatically Unavailable Constituents during Sentence Processing. Journal of Experimental Psychology: Learning, Memory, and Cognition 33 (2): 407-430.

Walker, M.A. \& Prince, E.F. 1996. A Bilateral Approach to Givenness: A Hearer-Status Algorithm and a Centering Algorithm. In T. Fretheim and J.K. Gundel (eds.), Reference and Referent Accessibility. Amsterdam - Philadelphia: J. Benjamins: 29I-306.

XIANG, M., Dillon, B.W. \& Phillips, C. 2009. Illusory Licensing Effects across Dependency Types: ERP Evidence. Brain and Language I08 (I): 40-55. 


\section{Appendix A}

The following list of sentences was tested in the Experiment $\mathrm{I}$. The slash indicates a presentation boundary. The NPs within parentheses occurred in a subset of conditions.

I. The doctor's (nurse's) / brother (sister) / criticizes / himself (herself) / over / the most / insignificant things. /

2. The executive's (secretary's) / father (mother) / talks to / himself (herself) / when / no one / else / is around. /

3. The engineer's (librarian's) / uncle (aunt) / motivated / himself (herself) / to lose weight / by joining a weight loss / support group. /

4. The lawyer's (paralegal's) / grandfather (grandmother) / convinced / himself (herself) / that / a low fat diet would cure / high blood pressure. /

5. The coach's (babysitter's) / nephew (niece) / brags about / himself (herself) / to / the other kids in / the neighborhood. /

6. The pilot's (flight attendant's) / brother-in-law (sister-in-law) / shocked / himself (herself) / with such an outstanding / bowling / score. /

7. The butcher's (hairdresser's) / son (daughter) / drives / himself (herself) / to school / everyday in good weather / and in bad. /

8. The groom's (bride's) / dad (mom) / burned / himself (herself) / putting / the rolls / back / in the oven. /

9. The butler's (maid's) / stepson (stepdaughter) / hurt / himself (herself) / playing / on / the / monkey bars. /

Io.The attorney's (bookkeeper's) / father-in-law (mother-in-law) / entertained / himself (herself) / all / afternoon / with crossword puzzles. /

II. The sheriff's (florist's) / nephew (niece) / prepared / himself (herself) / to take / the / upcoming / ACT test. /

I2. The limo driver's (nanny's) / uncle (aunt) / watched / himself (herself) / on / the video tape / of the family reunion picnic. /

I3. The priest's (nun's) / grandfather (grandmother) / washed / himself (herself) / before / the hospice nurse / arrived. /

I4. The guard's (clerk's) / grandson (granddaughter) / dressed / himself (herself) / for / the first time last / Sunday. /

I5. The deputy's (typist's) / brother (sister) / cut / himself (herself) / on a piece / of / notebook / paper. /

16.The homicide detective's (kindergarten teacher's) / step-brother (stepsister) / embarrassed / himself (herself) / in front of the entire / coffee / shop. / 


\section{Appendix B}

The following list of sentences was tested in Experiment 2. The slash indicates a presentation boundary. The genitive NP either matched or mismatched in gender with the antecedent of the reflexive pronoun. The reflexive pronoun always matched in gender with the antecedent.

I. Mark's|Mary's brother|sister / criticizes / himself|herself / over / the most / insignificant / things. /

2. Dave's|Sara's father|mother / talks to / himself|herself / when / no one / else / is around. /

3. John's|Jane's uncle|aunt / motivated / himself|herself / to lose weight / by joining / a weight loss support group. /

4. Greg's|Jill's grandfather|grandmother / convinced / himself|herself / that / a low fat diet / would cure high blood pressure. /

5. Ted's|Sue's nephew|niece / brags about / himself|herself / to / the other kids / in / the neighborhood. /

6. Jim's|Ann's brother-in-law|sister-in-law / shocked / himself|herself / with such / an outstanding / bowling score. /

7. Bob's|Ruth's son|daughter / drives / himself|herself / to school / everyday / in good weather and in bad. /

8. Will's|Tina's dad|mom / burned / himself|herself / putting / the rolls / back / in the oven. /

9. Gary's|Tammy's stepson|stepdaughter / hurt / himself|herself / playing / on / the / monkey bars. /

Io.Henry's|Brenda's father-in-law|mother-in-law / entertained / himself|herself / all / afternoon / with crossword puzzles. /

II. Bill's|Rita's nephew|niece / prepared / himself|herself / to take / the / upcoming / ACT test. /

I2.Mike's|Lori's uncle|aunt / watched / himself|herself / on / the video tape / of the family reunion picnic. /

I3. Brad's|Lisa's grandfather|grandmother / washed / himself|herself / before / the hospice / nurse / arrived. /

I4. Robert's|Barbara's grandson|granddaugher / dressed / himself|herself / for / the first time / last / Sunday. /

I5. Rick's|Donna's brother|sister / cut / himself|herself / on a piece / of / notebook / paper. /

I6.Phil's|Cathy's step-brother|step-sister / embarrassed / himself|herself / in front of / the / entire / class. / 